\title{
Banner clouds observed at Mount Zugspitze
}

\author{
V. Wirth ${ }^{1}$, M. Kristen ${ }^{2}$, M. Leschner ${ }^{1}$, J. Reuder ${ }^{3}$, and J. H. Schween ${ }^{4}$ \\ ${ }^{1}$ Institute for Atmospheric Physics, Johannes Gutenberg-University, Mainz, Germany \\ ${ }^{2}$ Wetterwarte Garmisch-Partenkirchen/Zugspitze, Garmisch-Partenkirchen, Germany \\ ${ }^{3}$ Geophysical Institute, University of Bergen, Bergen, Norway \\ ${ }^{4}$ Institute for Geophysics and Meteorology, University of Cologne, Cologne, Germany
}

We dedicate this paper to the memory of the late Joachim Kuettner, who was our mentor throughout the project.

Correspondence to: V. Wirth (vwirth@uni-mainz.de)

Received: 19 September 2011 - Published in Atmos. Chem. Phys. Discuss.: 31 October 2011

Revised: 17 February 2012 - Accepted: 2 April 2012 - Published: 17 April 2012

\begin{abstract}
Systematic observations of banner clouds at Mount Zugspitze in the Bavarian Alps are presented and discussed. One set of observations draws on daily time lapse movies, which were taken over several years at this mountain. Identifying banner clouds with the help of these movies and using simultaneous observations of standard variables at the summit of the mountain provides climatological information regarding the banner clouds. In addition, a week-long measurement campaign with an entire suite of instruments was carried through yielding a comprehensive set of data for two specific banner cloud events.
\end{abstract}

The duration of banner cloud events has a long-tailed distribution with a mean of about $40 \mathrm{~min}$. The probability of occurrence has both a distinct diurnal and a distinct seasonal cycle, with a maximum in the afternoon and in the warm season, respectively. These cycles appear to correspond closely to analogous cycles of relative humidity, which maximize in the late afternoon and during the warm season. In addition, the dependence of banner cloud occurrence on wind speed is weak. Both results suggest that moisture conditions are a key factor for banner cloud occurrence. The distribution of wind direction during banner cloud events slightly deviates from climatology, suggesting an influence from the specific Zugspitz orography.

The two banner cloud events during the campaign have a number of common features: the windward and the leeward side are characterized by different wind regimes, however, with mean upward flow on both sides; the leeward air is both moister and warmer than the windward air; the background atmosphere has an inversion just above the summit of Mt.
Zugspitze; the lifting condensation level increases with altitude. The results are discussed, and it is argued that they are consistent with previous Large Eddy Simulations using idealized orography.

\section{Introduction}

Banner clouds are cloud plumes which extend downwind of steep mountains or sharp ridges even on otherwise cloudfree days (Glickman, 2000). Examples are the banner clouds at Matterhorn in the Swiss Alps or at Mount Zugspitze in the Bavarian Alps (see Fig. 1). Although this beautiful phenomenon is generally well known, only very few observational reports can be found in the scientific literature (Peppler 1927; Küttner 2000). Based on a set of time lapse movies taken on Mount Zugspitze, Schween et al. (2007) provided a detailed definition of what should (and what should not) be considered a banner cloud. According to their analysis, a banner cloud must simultaneously satisfy four criteria: (1) the cloud should be in a fixed relation to the mountain and occur only on its leeward side; (2) the cloud should not be composed of snow crystals blown off the mountain by the wind; (3) the cloud should be persistent; (4) the cloud should not be primarily of convective character. The last criterion is meant to distinguish banner clouds from purely convective clouds on days with vanishing mean wind.

Several authors attempted to uncover the key physical ingredients of a banner clouds. Essentially three hypotheses have emerged, explaining banner clouds as due to either the 


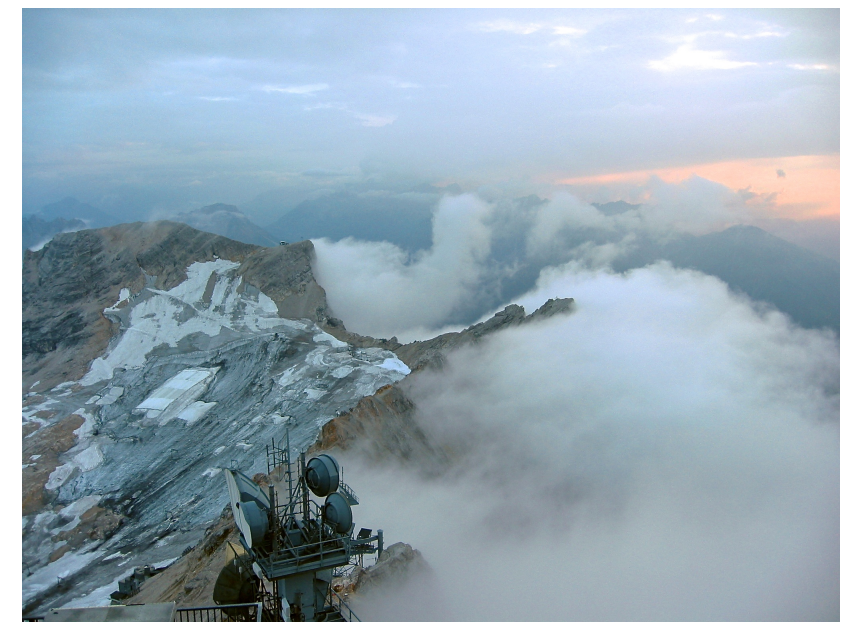

Fig. 1. Banner cloud at Mount Zugspitze on 1 July 2002. The wind is blowing from left to right. The photograph was taken from the summit of the mountain viewing southwestwards.

Bernoulli effect (Humphreys 1920; Grant 1944; Huschke 1959; Beer 1974), due to mixing fog (Humphreys 1920), or due to a lee vortex (Hann 1896; Douglas 1928; Hindman and Wick 1990; Geerts 1992a, 1992b). The observations of Schween et al. (2007) favor the latter theory, but their conclusions are merely based on time lapse movies of a few selected banner cloud events. Also, the idealized numerical simulations of Reinert and Wirth (2009) indicate that lee vortices on pyramidal shaped mountains are likely to give rise to banner clouds.

Clearly, progress in the past has been limited by the shortage of systematic observations. A few years ago we, therefore, decided to significantly enhance the observational basis by installing an entire suite of automatically operating instruments on Mount Zugspitze, where banner clouds are known to occur regularly (Küttner, 2000). Some of these instruments provided quasi-continuous observations over a timespan of several years. In addition, we carried through a measurement campaign during one week in October 2005. There were two banner cloud events during this week, and we collected a large number of additional data for these two events. It is the goal of the current paper to present the highlights derived from both the long-term observations and the measurement campaign.

The plan of the paper is as follows. In the next section we give an overview of the various instruments and describe their modes of operation. We proceed in Sect. 3 to quantitatively evaluate our time lapse movies providing statistics regarding the occurrence of banner clouds at Mount Zugspitze. Section 4 then presents the main results from the campaign, providing a comprehensive set of data for two specific banner cloud events. Finally, we discuss the results in Sect. 5 and draw our conclusions.

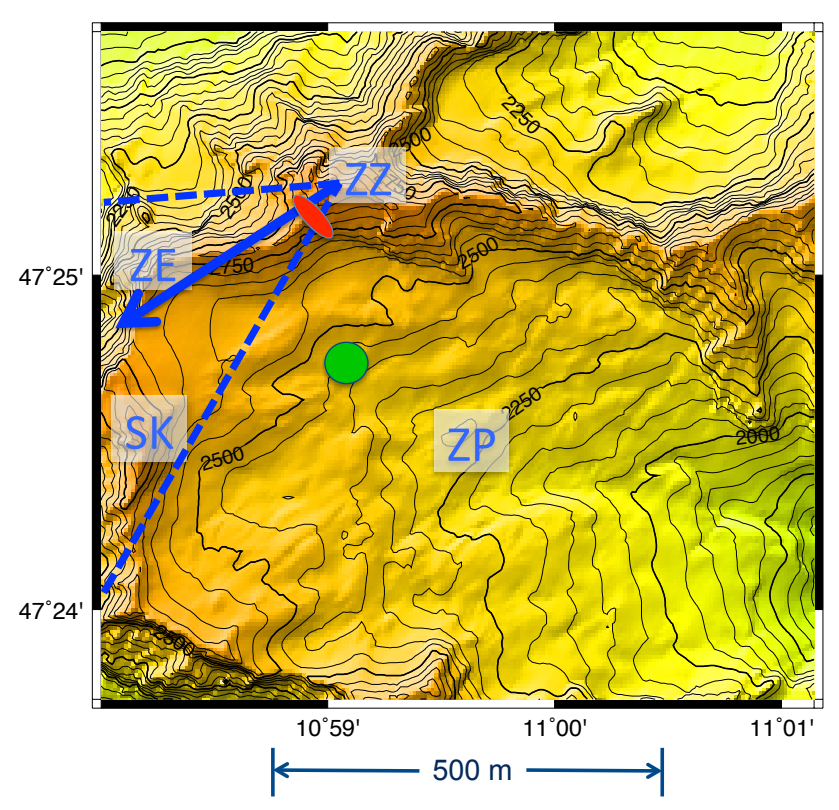

Fig. 2. Map of Mount Zugspitze (Mercator projection) with the main landmarks: summit of Mt. Zugspitze (ZZ, $2962 \mathrm{~m}$ ), Zugspitzeck (ZE, 2816 m), Schneefernerkopf (SK, $2874 \mathrm{~m}$ ), and Zugspitzplatt (ZP). North is towards the top of the figure. The black contours indicate the height of the orography above sea level. The blue arrow represents the viewing direction of the digital camera, and the blue dashed lines its $55^{\circ}$ field of view. The location of the masts is indicated by the red oval immediately southwest of the summit. The pilot balloons and the Kali airplane were launched from a location which is represented by the green circle. The area shown is slightly less than $1 \mathrm{~km}^{2}$.

\section{Observation methodology}

Figure 2 gives an overview of the topography of Mount Zugspitze with its main landmarks. In particular, the ridge connecting the summit of Mt. Zugspitze (ZZ) and the Zugspitzeck (ZE) will be refered to as "the ridge" in the following. Banner clouds were observed on either side of "the ridge", as well as on the eastern side of a ridge connecting Zugspitzeck and Schneefernerkopf. Altitudes are given in meters above sea level (unless specified otherwise); local time is given in Central European Time (CET), corresponding to UTC +1 (where UTC is Universal Time Coordinated).

The following subsections describe the different observation systems which were used for our study.

\subsection{Digital camera}

A digital camera (M12, MOBOTIX, Germany) was installed on the meteorological observatory at the summit of Mt. Zugspitze, looking southwestwards along the ridge connecting the summit of Mt. Zugspitze with Zugspitzeck (Fig. 2; for details and sample movies see Schween et al. 2007). The camera was connected to a Linux computer, which recorded 

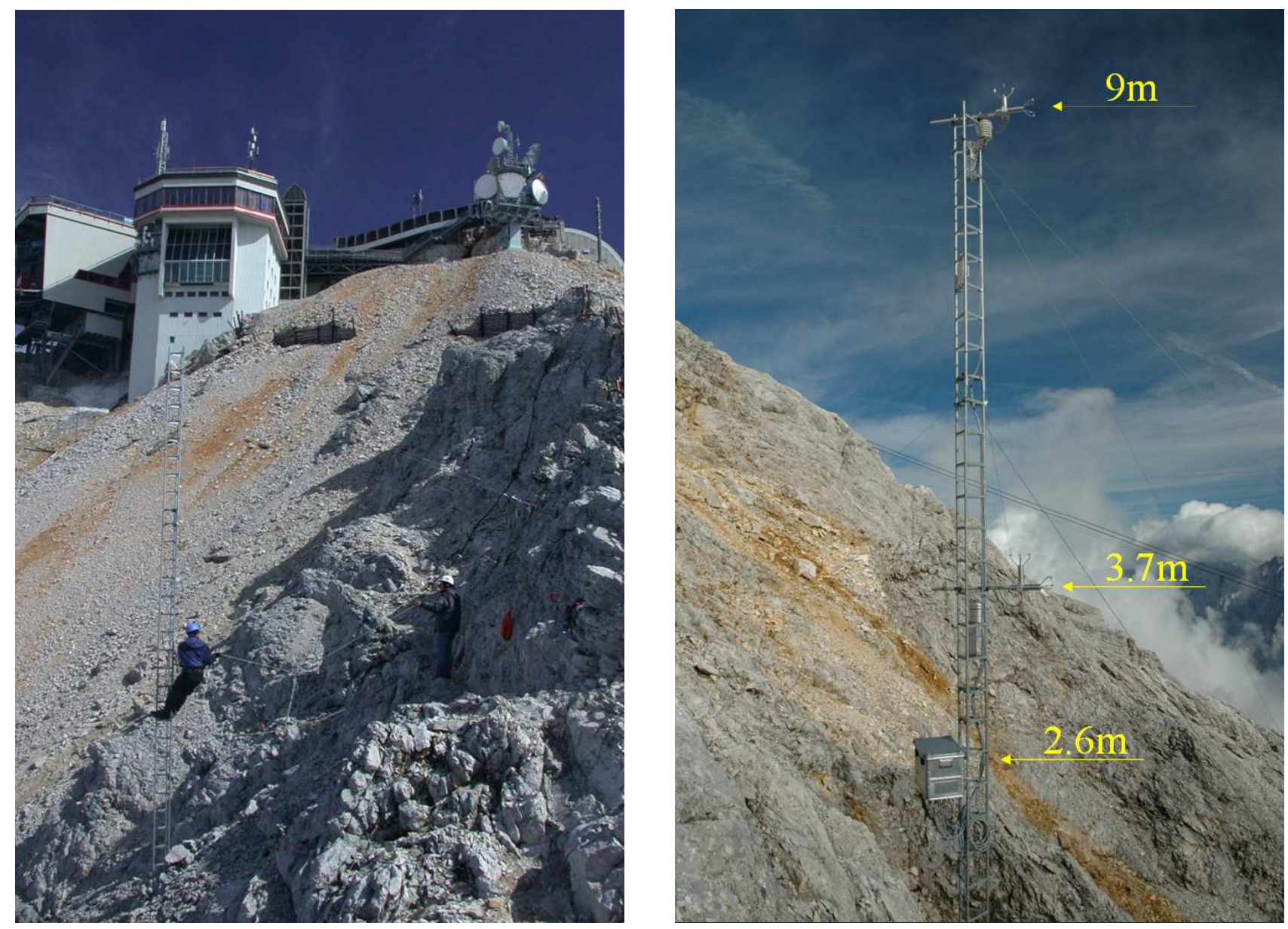

Fig. 3. Photographs showing the two masts, one on the northern side (left panel) and the other one on the southern side (right panel) of the ridge. The view is from the southwest looking upwards toward the summit of Mt. Zugspitze. Measurements at each mast are taken at two heights, namely 3.7 and $9 \mathrm{~m}$ above ground.

one image $(640 \times 480$ pixels $)$ every $5 \mathrm{~s}$ during daylight hours, i.e. from approximately 30 min before sunrise until approximately $30 \mathrm{~min}$ after sunset. The images were converted into standard mpeg-1 time lapse movies during the following night. The camera was operational between December 2002 and October 2006. Altogether we obtained time lapse movies for 797 days from 38 different months. The corresponding statistics are summarized in Table 1.

\subsection{Meteorological data from the summit of Mt. Zugspitze}

The German Weather Service operates a weather station at the summit of Mt. Zugspitze, providing a wealth of in situ observations. In this work we used hourly data (with only very few gaps) of wind and relative humidity spanning the range 1 January 2002-31 December 2006. Based on these data we computed climatologies of the respective variables.

\subsection{Masts at the ridge}

Two $9 \mathrm{~m}$ masts were installed, one on either side of the ridge at roughly the same altitude, located approximately $120 \mathrm{~m}$ southwest of the summit of Mt. Zugspitze (see Fig. 2). Two photographs are shown in Fig. 3. The masts are about $15 \mathrm{~m}$ apart, one on the northern and the other one on the southern side of the ridge. Instruments were mounted at 3.7 and $9 \mathrm{~m}$ above the foot of the mast, such that the lower position was well below the ridge and the upper position was slightly above the ridge. The mast location was just outside the field of view of the digital camera.

At both measurement heights the masts were equipped with sensors for wind, temperature, and humidity. Wind was measured using 2-D heated sonic anemometers (Windobserver II, Gill, UK). They were chosen for their robustness and a heating option, which proved to be very useful during cloud episodes at temperatures below $0{ }^{\circ} \mathrm{C}$. Two anemometers were mounted at each height, one horizontally and one 
vertically, respectively, such that all three components of the wind vector could be measured. Temperature and humidity were measured with combined temperature and humidity sensors (Fischer, Germany). The latter were installed in ventilated radiation shields. At the upper position we installed additional, more robust sensors for both temperature and humidity (HMP243, Vaislala, Finland). The Vaisala humidity sensor is a heated Humicap ${ }^{\circledR} \mathrm{KC}$ sensor also used in the Vaisala RS90 radiosondes. Heating the sensor improves the accuracy of the humidity readings especially under fast changing conditions at high relative humidity, when condensation on the sensor renders measurements difficult. Fischer uses a standard capacitive humidity sensor (HIH-3605, Honeywell, USA) which delivers voltages proportional to relative humidity. Prior to installation the temperature sensors were calibrated in a climate chamber (relative to a calibrated reference Pt100), resulting in an accuracy better than $0.05 \mathrm{~K}$ within the range $-30{ }^{\circ} \mathrm{C}$ to $+30^{\circ} \mathrm{C}$.

A box mounted at $2.6 \mathrm{~m}$ above the foot of each mast housed power supply, data logger and a pressure sensor (Fischer, Germany). Data were measured every $2 \mathrm{~s}$ and stored as $5 \mathrm{~min}$ averages by electronic data loggers (Combilog, Theodor Friedrichs, Germany). They were transferred via mobile phone around midnight every day.

The masts were installed in September 2005. In December 2005 the north mast collapsed in a storm. The southern mast remained in operation until November 2006 and stood until September 2008, when it was removed.

\subsection{Measurement campaign}

In order to complement the information from the long-term measurements, an intensive observation campaign was conducted in Autumn 2005. Measurements took place during 6-7 and 11-13 October. Two occurrences of a banner cloud were sampled with all instruments up and running: one on 6 October and a second one on 11 October.

Radiosondes (RS90, Vaisala, Finland) were launched three times a day (in the morning, around noon, and in the afternoon) from the office of the German Weather Service (DWD) in Grainau, which is located on the valley floor about $10 \mathrm{~km}$ northeast of the summit of Mt. Zugspitze at $720 \mathrm{~m}$ altitude. Profiles of potential temperature were obtained through $\theta=T\left(p_{0} / p\right)^{R / c_{p}}$, where $p$ is pressure, $p_{0}=1000 \mathrm{hPa}, R$ is the gas constant for dry air, and $c_{p}$ is the specific heat at constant pressure.

A remote controlled miniature airplane called "Kali" was launched from Zugspitzplatt at $2575 \mathrm{~m}$ altitude to provide profiles of temperature and humidity. In total 14 flights were performed, reaching heights between 550 and $1280 \mathrm{~m}$ above the starting altitude. This measurement system was described in more detail by Egger et al. (2002).

A total of 42 pilot balloons were launched on an hourly basis and tracked typically several $100 \mathrm{~m}$ above the starting point. They provided wind profiles above the Zugspitzplatt.
Table 1. Overview of the time lapse movies: each row represents a climatological month, the number of days with available data (i.e. with the digital camera operating) is denoted by $N_{\mathrm{d}}$, the number of observed banner cloud days is denoted by $N_{\mathrm{bc}}$, the duration of the daily operations is denoted by $T_{\mathrm{d}}$. As an estimate for the statistical error we use $\Delta N_{\mathrm{bc}}=\sqrt{N_{\mathrm{bc}}}$.

\begin{tabular}{lrrrr}
\hline & $N_{\mathrm{d}}$ & $N_{\mathrm{bc}}$ & $\Delta N_{\mathrm{bc}}$ & $T_{\mathrm{d}}(\mathrm{h})$ \\
\hline Jan & 58 & 2 & 1.4 & 9.8 \\
Feb & 87 & 10 & 3.2 & 11.2 \\
Mar & 104 & 20 & 4.5 & 12.8 \\
Apr & 62 & 18 & 4.2 & 14.6 \\
May & 45 & 18 & 4.2 & 16.2 \\
Jun & 65 & 25 & 5.0 & 17.1 \\
Jul & 55 & 17 & 4.1 & 16.7 \\
Aug & 58 & 16 & 4.0 & 15.4 \\
Sep & 49 & 20 & 4.5 & 13.7 \\
Oct & 68 & 12 & 3.5 & 11.9 \\
Nov & 71 & 7 & 2.6 & 10.1 \\
Dec & 75 & 5 & 2.2 & 9.3 \\
\hline Total & 797 & 170 & & \\
\hline
\end{tabular}

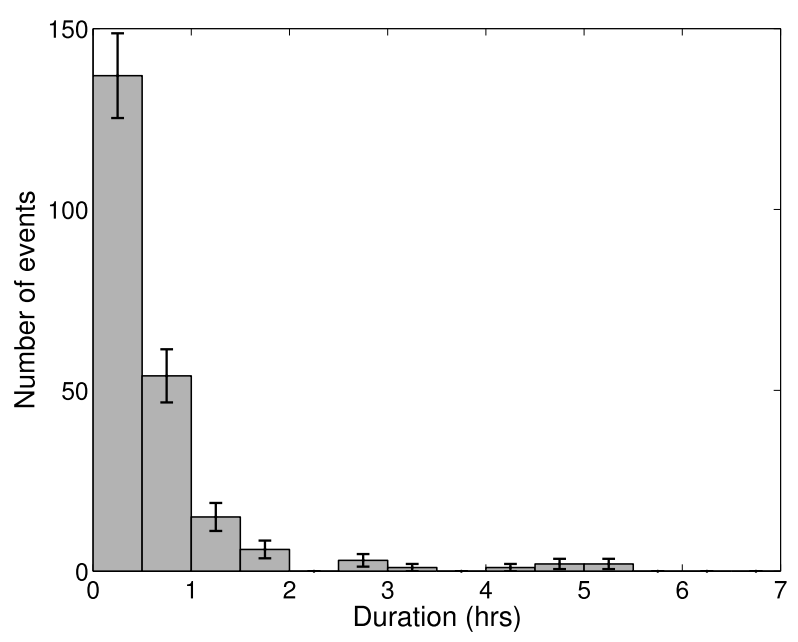

Fig. 4. Distribution of the duration of the observed banner cloud events. The error bars represent the statistical error; they are equal to $\pm \sqrt{n}$, with $n$ denoting the number of events in each bin.

A detailed description of the pilot balloon tracking system can be found in Egger (1999).

\section{Banner cloud statistics}

Each occurrence of a banner cloud according to the definition by Schween et al. (2007) is called a banner cloud event. In ambigous cases we decided to be conservative in the sense that only those events were taken into account which clearly satisfied our criteria. Ambiguous cases included cases with blowing snow, clouds which were at least 

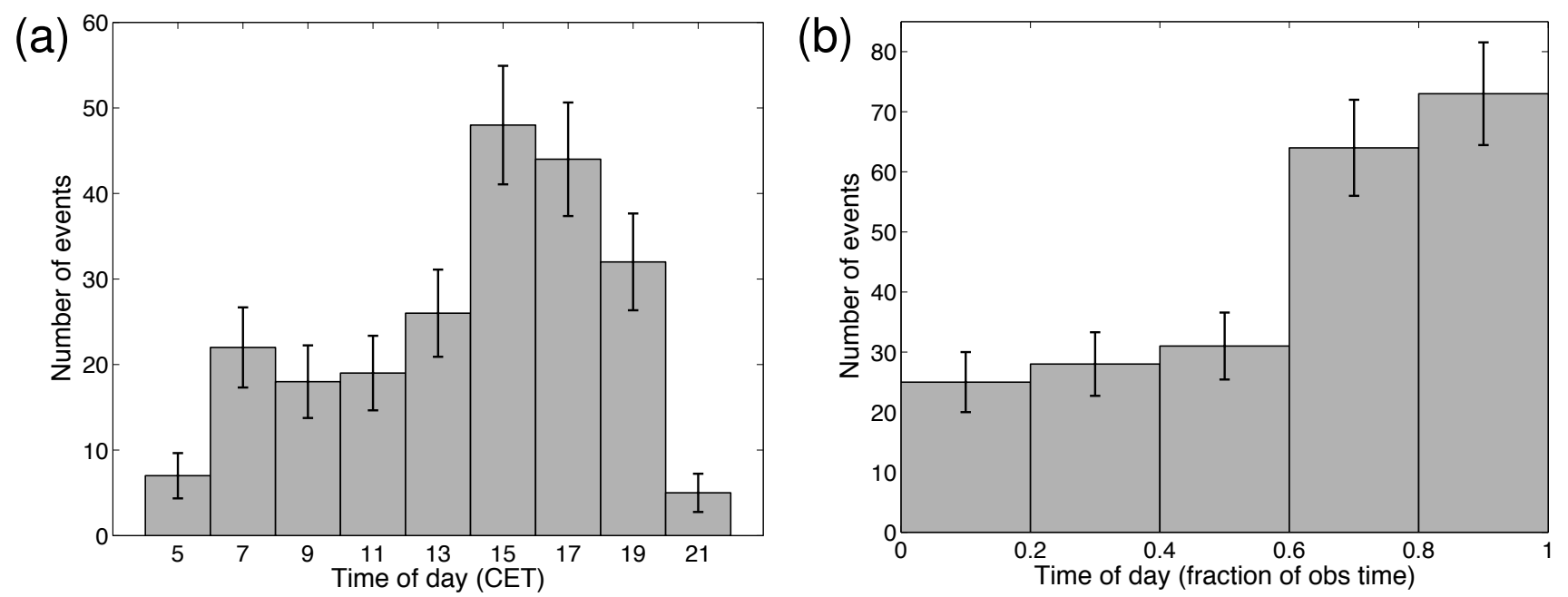

Fig. 5. Distribution of the time of occurrence of the observed banner cloud events. Panel (a) bins the different events in terms of the hour of occurrence in CET, while panel (b) bins the different events in terms of time relative to the time interval of daily operations (see text). The error bars represent the statistical error; they are equal to $\pm \sqrt{n}$, with $n$ denoting the number of events in each bin.

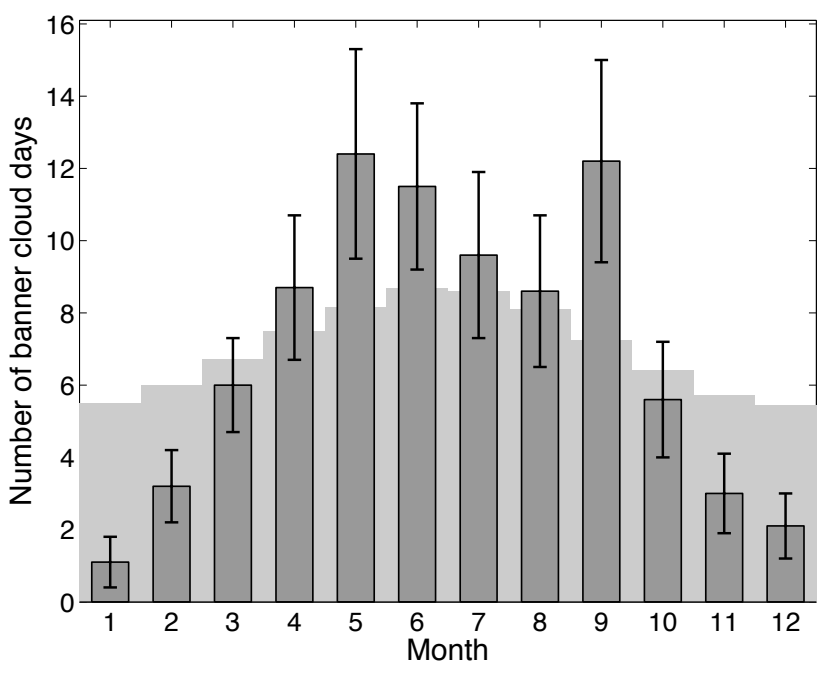

Fig. 6. Seasonal cycle of banner cloud occurrence. The dark bars indicate the average number of observed banner cloud days as a function of climatological month (with the error bars quantifying the statistical error). The light grey background histogram represents a hypothetical distribution for which the same total number of events is distributed according to the length of daylight.

partly of convective character, or cases with only brief occurrences of a cloud in the lee and otherwise lots of clouds around the ridge. For each banner cloud event we registered the time of onset and decay of the banner cloud. Each day on which at least one banner cloud event was detected is called a banner cloud day. The numbers $N_{\mathrm{bc}}$ of observed banner cloud days are given in the second column of Table 1 . The total number of banner cloud days during the four-year pe- riod was 170 . On some of these days we observed more than one banner cloud event, yielding a total of 221 banner cloud events.

The mean duration of a banner cloud event was $40 \mathrm{~min}$. The distribution of the duration is shown in Fig. 4. It is highly skewed with a dominance of short events of less than half an hour, but the distribution has a long tail representing a few events that lasted for several hours.

Banner clouds were observed throughout the day. Figure 5 a shows the distribution of the banner cloud events as a function of the time of day. The most frequent occurrence of banner clouds is in the afternoon between 14:00 and 18:00 CET. However, care needs to be exercised when interpreting this histogram, since a summer day has more hours of daylight than a winter day. As mentioned before, our digital camera was operational each day approximately from $30 \mathrm{~min}$ before sunrise until $30 \mathrm{~min}$ after sunset. Here, we define the duration of the daily operations $T_{\mathrm{d}}$ as the time interval from $30 \mathrm{~min}$ before sunrise to $30 \mathrm{~min}$ after sunset (third column of Table 1). The boundaries of this interval were determined for the 15th of each month and interpolated to each day of the year. We then calibrated the time of occurrence of each banner cloud event with respect to the time interval of daily operations. The corresponding histogram is provided in Fig. 5b. Apparently, the chance of occurrence of a banner cloud event on a given day has a distinct diurnal cycle, starting with low values in the morning and increasing to much larger values in the late afternoon; the maximum rate of occurrence during the late afternoon is almost three times as large as the minimum rate of occurrence in the morning. Analyzing the individual seasons separately (no plots shown), we found approximately the same qualitative behavior for all 

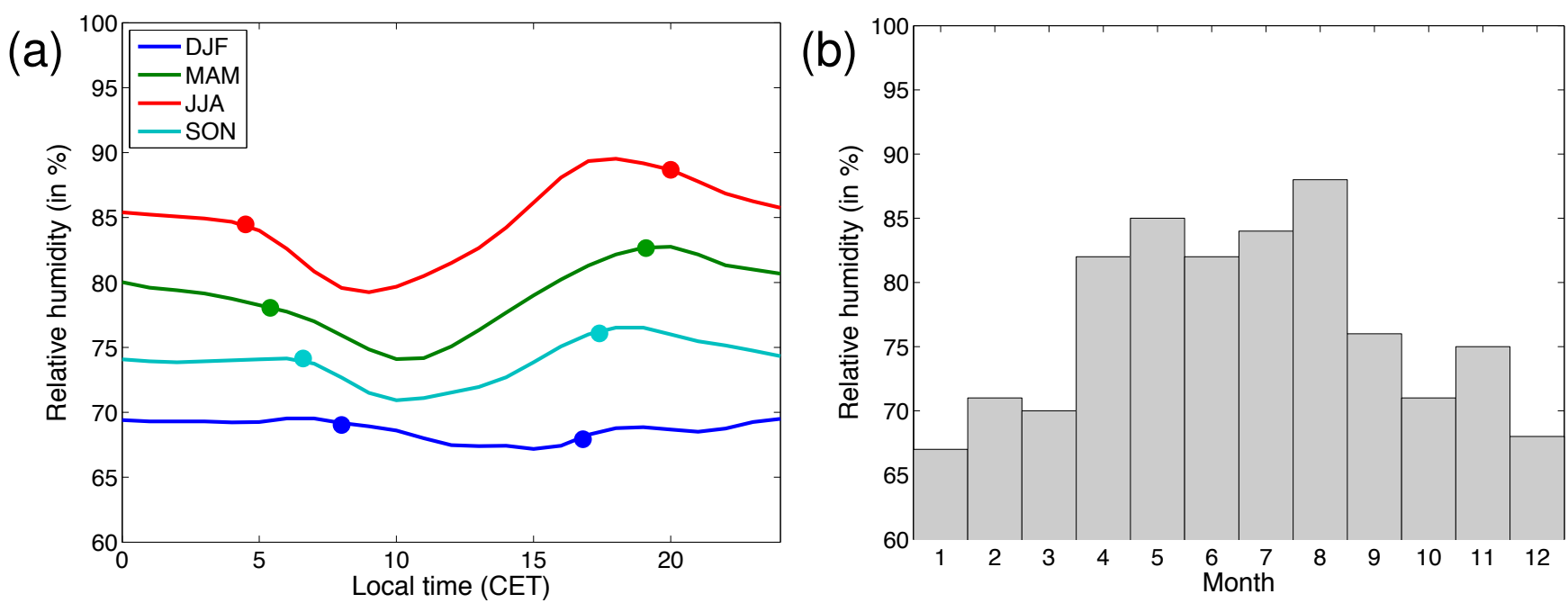

Fig. 7. Climatology of relative humidity at the summit of Mt. Zugspitze: (a) diurnal cycle, and (b) seasonal cycle. The colored dots in panel (a) indicate the time of sunrise and sunset at the middle of the respective seasons.
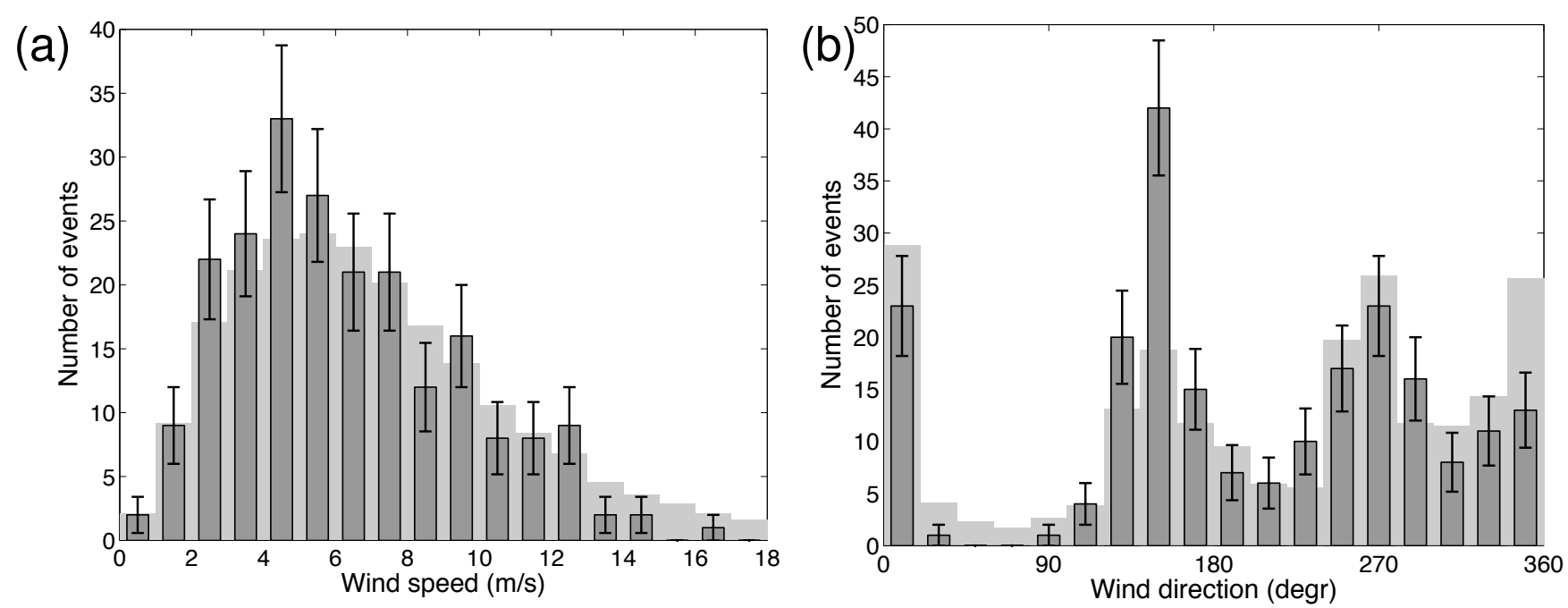

Fig. 8. Histogram of (a) wind speed and (b) wind direction. The dark bars represent the number $n$ associated with banner cloud events, with the error bar denoting $\pm \sqrt{n}$; the light grey background histograms represent the respective climatologies, which have been normalized such as to contain the same total number of events. Bin size is $1 \mathrm{~m} \mathrm{~s}^{-1}$ in (a) and $20^{\circ}$ in (b).

seasons except winter, but the number of available observations was slightly too limited to provide robust statistics.

Banner clouds occurred throughout the year, although not with the same frequency in all seasons. The dark bars in Fig. 6 represent the climatology for the number of banner cloud days per month, computed from the numbers in Table 1 as $N_{\text {bc }} / N_{\mathrm{d}} \times$ (number of days per month). Apparently, there is a clear seasonal cycle with much larger numbers in summer (approx. 10 per month) than in winter (approx. 2 per month). However, interpreting these numbers requires care because, again, the seasonal cycle of the daylight time needs to be accounted for: at winter solstice the duration of daily operations $T_{\mathrm{d}}$ is around $10 \mathrm{~h}$, while at summer solstice it is around $17 \mathrm{~h}$ (see Table 1). For this reason, the plot in Fig. 6 contains another histogram (light grey) representing a hypothetical distribution which one would obtain by assuming that the total number of observed banner cloud days is distributed according the duration of the daily operations. Comparing these two distributions reveals that the seasonal cycle of observed banner cloud days is significantly more pronounced than the seasonal cycle of the duration of daily operations. We conclude that the probability of occurrence of a banner cloud day has a distinct seasonal cycle: it is significantly larger during the warm season than during the cold season. 
What is the underlying reason for these distinct diurnal and seasonal cycles of banner cloud occurrence? In this context, the availability of moisture is expected to play an important role. For this reason we used the humidity data from the summit (see Sect. 2.2) in order to compute a climatology of the diurnal and the seasonal cycles of relative humidity. The results are shown in Fig. 7a and b, respectively. Except in the winter season, the diurnal cycle shows a pronounced minimum a few hours after sunrise, followed by a monotonic increase, reaching a maximum in the late afternoon or early evening; at night the values are intermediate. Restricting attention to the daylight hours, the rise of relative humidity during the day is similar to the increase of banner cloud occurrence in Fig. 5b. Presumably, the decrease in relative humidity during the morning hours results from a temperature increase due to solar radiation, which heats the ground and the air adjacent to the ground. The increase in relative humidity during the day is likely to result from - on average - the onset of thermal circulations, which advect moister air from below up to the summit level.

Do the banner clouds have a preference for a certain wind speed or wind direction? In order to address this question, we analyzed wind data from the summit (see Sect. 2.2). Climatological information is obtained by using the full data set. In addition, wind characteristics during the presence of a banner cloud are obtained by selecting only those data which coincide with a banner cloud event.

A histogram of wind speed for all banner cloud events is shown in Fig. 8a (dark bars). Apparently, banner clouds can occur for almost any wind speed. Comparing this histogram with the corresponding climatology (light gray background histogram in Fig. 8a) indicates that, given our statistics, at least for the bulk of wind speeds $|\boldsymbol{v}|<13 \mathrm{~m} \mathrm{~s}^{-1}$ there is hardly any significant difference. This suggests that the existence of a banner cloud is essentially independent of wind speed.

The histogram for wind direction is shown in Fig. 8b (dark bars). There are three maxima: two of these (approximately northerly and southeasterly) correspond to flow which is approximately perpendicular to the ridge, from opposing directions. The third maximum is for westerly flow; in this case the respective banner clouds occur along the ridge connecting Zugspitzeck and Schneefernerkopf (see Fig. 2); the latter runs roughly north-south such that westerly flow corresponds to flow at right angles to that ridge. The angle distribution in $8 \mathrm{~b}$ broadly reflects the climatology (light grey background histogram), except that the banner cloud sample seems to slightly avoid the northerly direction and slightly prefer the southeasterly direction.

\section{Results from the measurement campaign}

There were two banner cloud events during our intensive observation period in October 2005: the first on 6 October, and the second on 11 October. The banner cloud on 6 October persisted for over five hours and was clearly identifiable throughout this time. The event on 11 October, by comparison, was shorter and more intermittent.

\subsection{October 2005}

The banner cloud on 6 October was clearly visible between 12:30 and 18:00 CET. Wind conditions on the ridge throughout the day are displayed in Fig. 9. Denoting the threedimensional wind vector by $\boldsymbol{u}=(u, v, w)$, the wind speed (panels a and b) is given by $|\boldsymbol{u}|=\sqrt{u^{2}+v^{2}+w^{2}}$, the angle $\alpha$ with respect to the horizontal (panels e and $\mathrm{f}$ ) is computed as $\alpha=\arctan \left(w / \sqrt{u^{2}+v^{2}}\right)$, and the horizontal wind direction (panels $\mathrm{c}$ and $\mathrm{d}$ ) is obtained similarly from $u$ and $v$.

Throughout the day, the wind on the windward side was blowing steadily from southeast, which is at right angles toward the ridge (Fig. 9a and c); the wind speed during the banner cloud event was between 3 and $5 \mathrm{~m} \mathrm{~s}^{-1}$ at $z=3.7 \mathrm{~m}$ and between 4 and $6 \mathrm{~m} \mathrm{~s}^{-1}$ at $z=9 \mathrm{~m}$, indicating a distinct vertical shear. By contrast, on the leeward side the wind direction was not at right angle towards the ridge; the wind speed was between 1 and $1.5 \mathrm{~ms}^{-1}$ at both $z=3.7 \mathrm{~m}$ and $z=9 \mathrm{~m}$ (Fig. 9b) with large fluctuations in direction (Fig. 9d). The angle $\alpha$ is close to $45^{\circ}$ on the southern side throughout the day (Fig. 9e), while it features a broad distribution on the northern side (Fig. 9f). Note, however, that on average the vertical component on the leeward side is upward, too. Interestingly, the termination of the banner cloud event around 18:00 CET is accompanied by an increase in wind speed on both the windward and the leeward side (panels a and $b$ ) and a change in direction on the leeward side (panels $d$ and $f$ ). This suggests that the termination of this banner cloud may be at least partly due to a change in the dynamical conditions.

In addition to the measurements on the ridge, we obtained wind profiles above the Zugspitzplatt from the pilot balloon ascents in the late morning and early afternoon (not shown). They indicated flow from east to southeast with large fluctuations of wind speed (both in time and space), increasing - on average - from about 3-4 $\mathrm{m} \mathrm{s}^{-1}$ right above the surface (at $2575 \mathrm{~m}$ altitude) to $6-8 \mathrm{~m} \mathrm{~s}^{-1}$ some $300 \mathrm{~m}$ above the surface.

Thermodynamic conditions during 6 October 2005 are summarized in Fig. 10. Panel d shows time series of temperature on both sides of the ridge. Interestingly, during the period of the banner cloud event (gray shading) the temperature on the leeward side (blue) is up to 2 degrees higher than on the windward side (red). On the other hand, the temperature difference between both sides is significantly less during the rest of the day. Regarding moisture (not shown), the leeward air mass is saturated throughout most of the day, while the windward airmass has a relative humidity varying between 
(a)
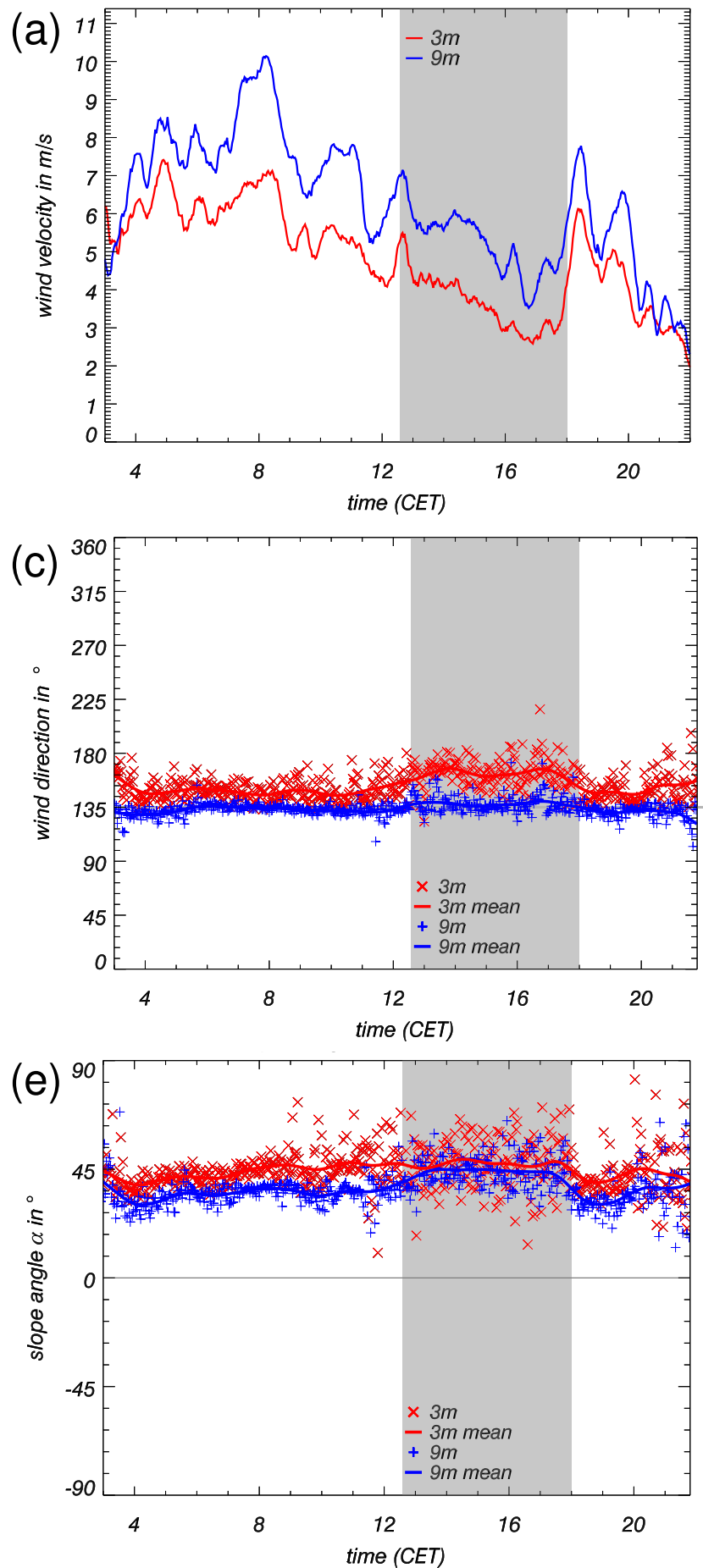
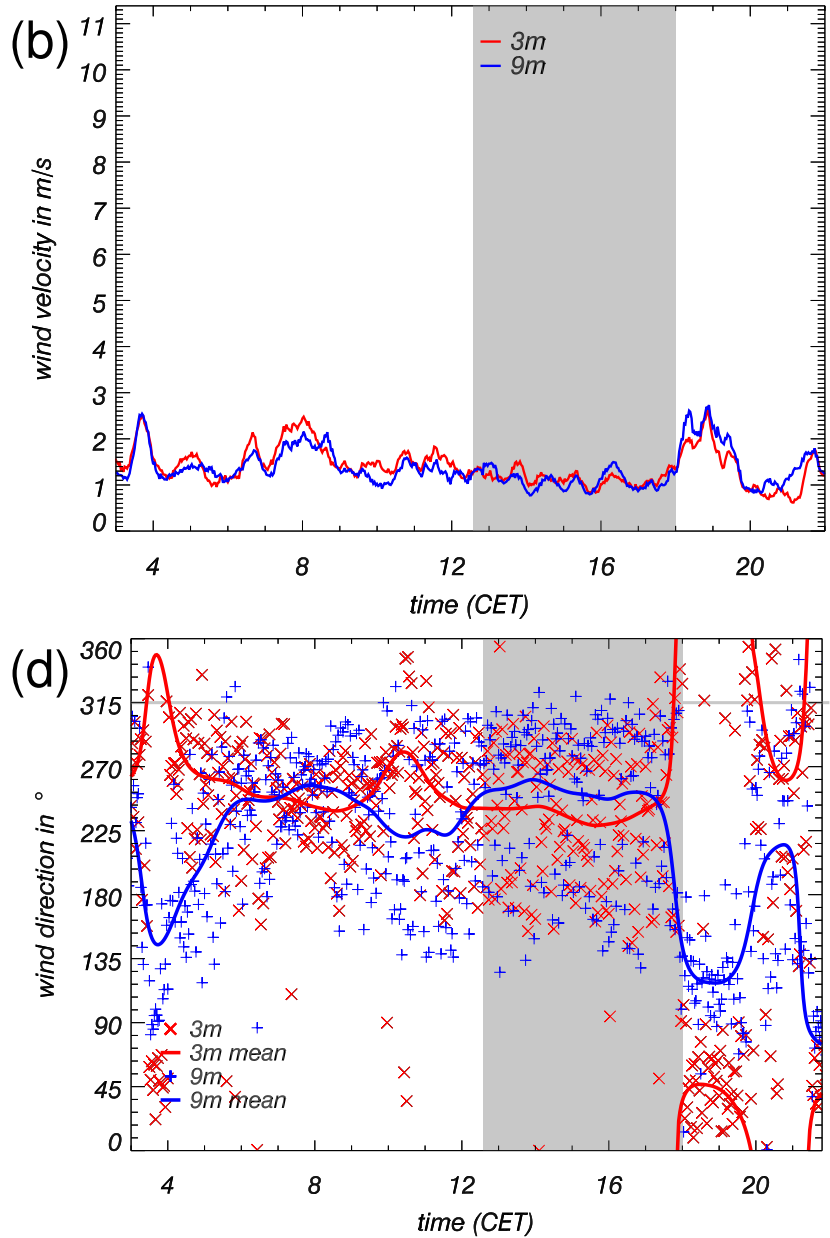

(f)

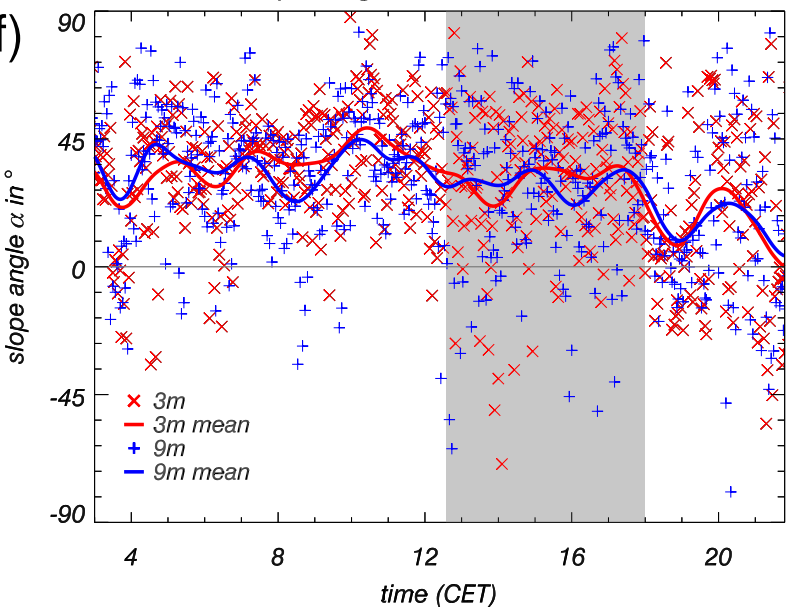

Fig. 9. Wind observations from the masts on both sides of the ridge on 6 October 2005. The left column represents the southern side, the right column represents the northern side of the ridge. (a) and (b): wind speed $\left(\mathrm{m} \mathrm{s}^{-1}\right)$, (c) and (d): wind direction (degrees), (e) and (f): angle of the wind vector with respect to the horizontal (degrees). Red color represents measurements at $3.7 \mathrm{~m}$ above ground, while blue color represents measurements at $9 \mathrm{~m}$ above ground. The straight gray lines in (c) and (d) indicate the direction corresponding to oncoming flow at right angles to the ridge; the straight grey lines in (e) and (f) indicate strictly horizontal flow. The thick solid blue and red lines in panels (c) through (f) delineate two-hour running means using a Hann window. The period during which a banner cloud was observed is denoted by gray shading. 
(a)
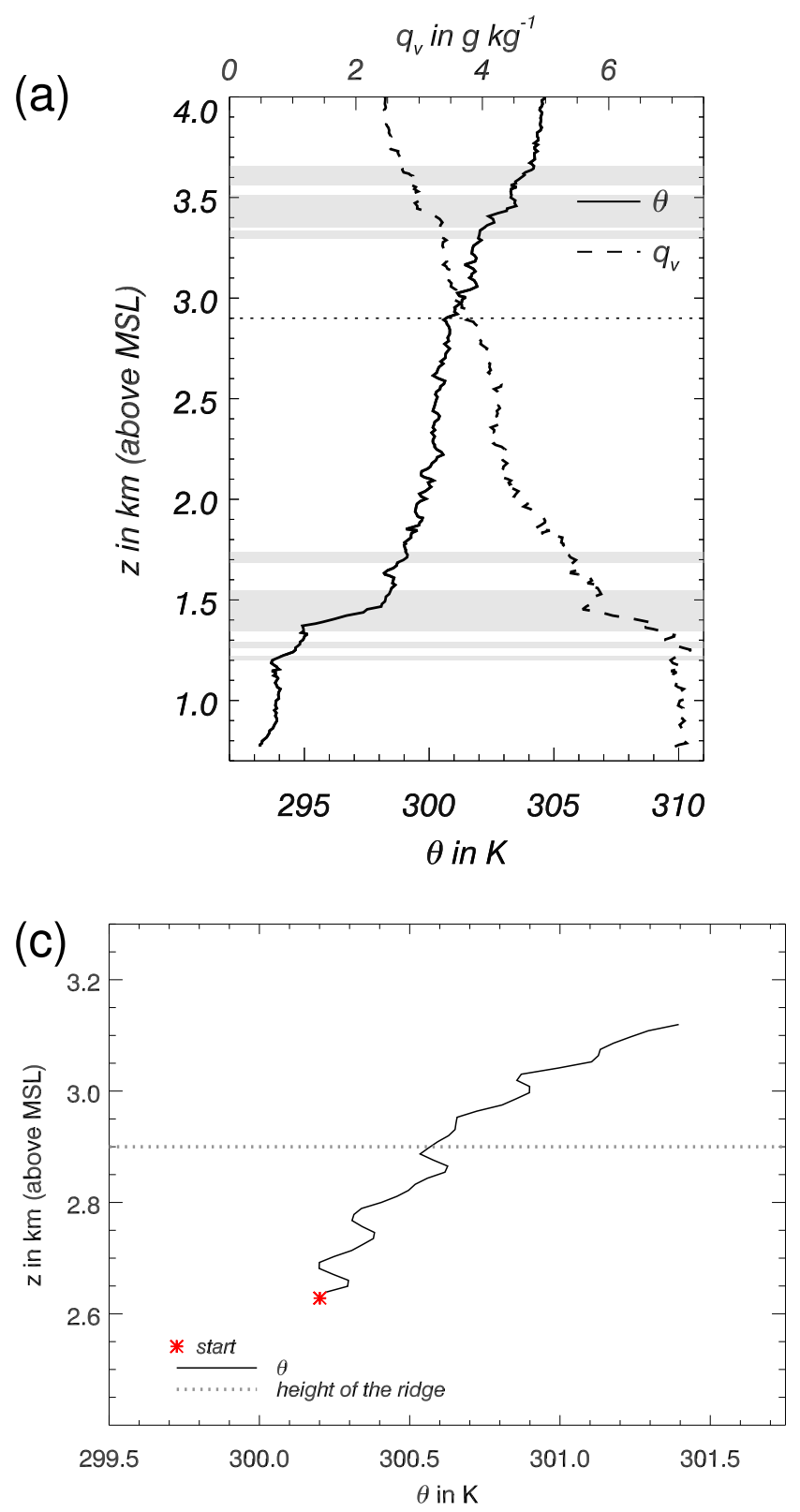

(b)

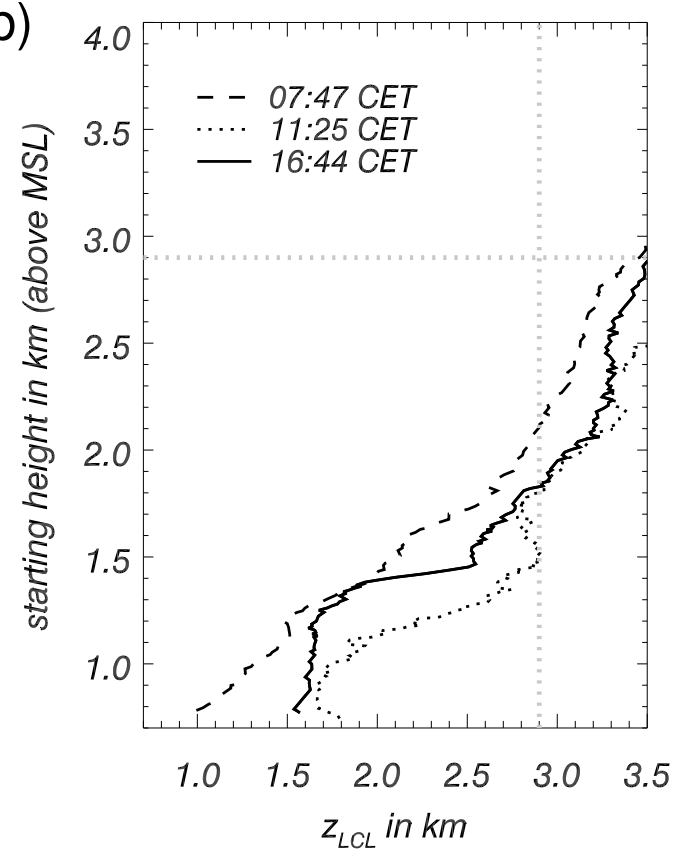

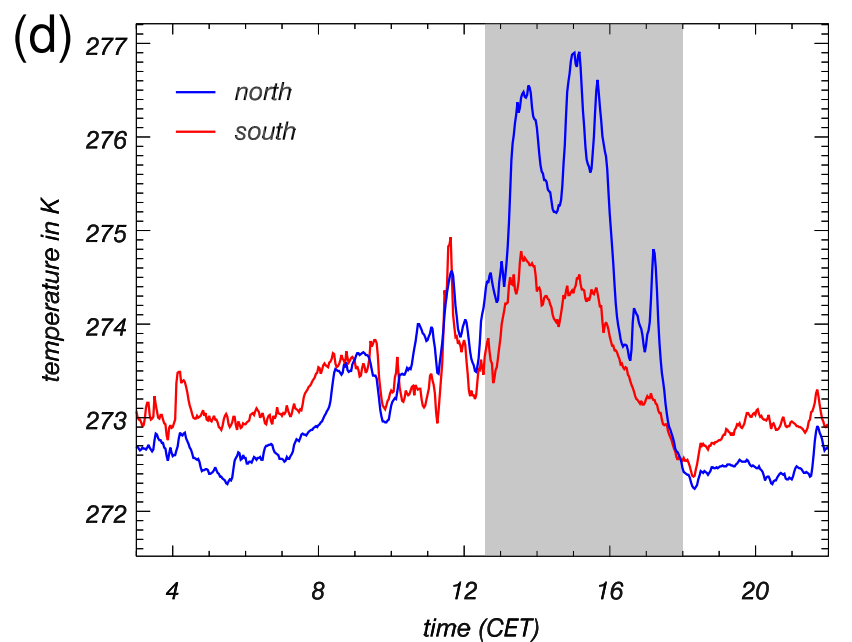

Fig. 10. Observations of thermodynamic conditions on 6 October 2006. (a) Profiles of potential temperature $\theta$ (solid) and specific humidity $q_{v}$ (dashed) from a radiosonde ascent made at the foot of Mount Zugspitze in Garmisch-Partenkirchen at 16:44 CET (launch time). Layers which are absolutely stable are indicated by grey shading. (b) Profiles of lifting condensation level $z_{\mathrm{LCL}}$ as a function of altitude, computed from the three radiosonde ascents which were made during the day. The legend for the different lines denotes the respective launch time. The latest ascent (solid line) corresponds to the ascent shown in (a). (c) Potential temperature $\theta$ from a Kali flight at 14:41 CET (launch time). The profile was computed as an average between the values from the ascent and the descent of the aircraft in order to minimize hysteresis effects; in addition, the profile was smoothed with a Hann window over 5 adjacent altitude bins. Take-off of the aircraft is denoted by an asterisk, and the altitude of the ridge is denoted by a straight dotted line. (d) Time series of temperature on the southern (red) and northern (blue) side of the ridge at $z=9 \mathrm{~m}$ above ground. The period during which the banner cloud was observed is indicated by gray shading.

90 and $100 \%$. During the period of the banner cloud, both sides are close to saturation, but again the leeward air mass is overall somewhat moister than the windward airmass.
The profiles from the radiosonde ascent (Fig. 10a) indicate a well-mixed boundary layer below $1300 \mathrm{~m}$. The level of the Zugspitze summit belongs to the free troposphere where potential temperature gradually increases and specific 
humidity gradually decreases with altitude. The boundary layer is topped by a strong inversion at $z=1400 \mathrm{~m}$, and there is an indication for a second weak inversion at around $z=3400 \mathrm{~m}$ a.s.l. Computing equivalent potential temperature $\theta_{e}$ (not shown) we obtained a profile which is rather close to a constant, with values varying between $315 \mathrm{~K}$ in the lowest part of the atmosphere and $313 \mathrm{~K}$ at $z=3000 \mathrm{~m}$ (i.e. at the level of the summit of Mt. Zugspitze). Analysing the radiosonde data we found essentially two layers with absolute stability, i.e. layers where the lapse rate $\gamma=-\partial T / \partial z$ is smaller than the moist adiabatic lapse rate (grey shading in Fig. 10a): one in the lower troposphere and a second one for $3300 \mathrm{~m}<z<3700 \mathrm{~m}$. Combining the temperature and moisture information from the radiosonde profiles we computed the lifting condensation level $\left(z_{\mathrm{LCL}}\right)$ associated with each altitude level (Fig. 10b). Overall, these profiles turn out to be increasing functions with altitude, indicating that the air is not well mixed in the vertical. In order to reach saturation at the summit level during the banner cloud event (solid line), a parcel would have to come from below $1850 \mathrm{~m}$ altitude. Earlier at 11:25CET (dotted line), when there was no banner cloud present, a parcel would have to come from below $1500 \mathrm{~m}$, which is unlikely as it would have had to cross the strong inversion.

The radiosonde ascent shown in Fig. 10a was downwind of the banner cloud event, and we take it as a rough indication for the typical environmental atmospheric conditions. In contrast, the Kali measurements shown in Fig. 10c were taken upwind of the banner cloud event; the corresponding potential temperature profiles are broadly consistent with the measurements from the radiosonde.

\subsection{October 2005}

The banner cloud on 11 October was visible between 16:20 and 18:10 CET, but it showed a rather intermittent behavior at the measurement site on the ridge. The background wind on that day turned from a northwesterly to a southeasterly direction at around 08:00 CET, as can be inferred from a change in wind direction and concomitant fluctuations at that time (Fig. 11c, d, e, and f). Simultaneously there is a conspicuous change in wind speed (Fig. 11a and b) resulting from the change in wind direction in combination with the steep orography.

Like on 6 October, we obtained wind profiles above the Zugspitzplatt from pilot balloon ascents in the late morning and early afternoon of 11 October (not shown). Here, the direction was southerly to southeasterly. The wind speed indicated, again, large fluctuations in time and space, increasing on average from about $2-3 \mathrm{~m} \mathrm{~s}^{-1}$ right above the surface (at $2550 \mathrm{~m}$ altitude) to about $3 \mathrm{~m} \mathrm{~s}^{-1}$ some $300 \mathrm{~m}$ above the surface. This is weaker than on 6 October, consistent with the generally weaker wind on the ridge (cf. Figs. 9a and 11a).

Time series of temperature on the ridge are shown in Fig. 12d. The temperature on the leeward side (blue) ex- ceeds that on the windward side (red) during most of the banner cloud event. This is qualitatively like on 6 October, but on 11 October the temperature excess is less than $1 \mathrm{~K}$ and does not stand out as clearly as on 6 October (cf. Fig. 10d). Incidentally, there is a reversed temperature difference during the morning hours in Fig. 12d with temperatures on the southern side exceeding those on the northern side by one to two degrees. Such a temperature difference was repeatedly observed on other days, too. It is almost certainly due to the influence of solar radiation leading to higher temperatures on the southern side of the ridge (which is exposed to the sun) than on its northern side (which lies in the shade). Although both 6 and 11 October were sunny during the morning hours, the effect of insolation on the temperature is not noticeable on 6 October (as opposed to 11 October, compare Fig. 10d and 12d), because on 6 October a strong wind was blowing from a southeasterly direction (see Fig. 9). On the other hand, on 11 October the southern side was in the lee until about 9 CET (see Fig. 11) and the wind speed was very small until that time, which - in combination with insolation - led to higher temperatures.

Regarding moisture during the banner cloud event (not shown), the leeward airmass was clearly saturated, while the windward airmass was subsaturated with relative humidity ranging between 85 and $95 \%$.

The radiosonde profiles on 11 October (Fig. 12a) show, again, a rather shallow boundary layer, topped by an inversion at $1100 \mathrm{~m}$ (i.e. approximately $400 \mathrm{~m}$ above the valley floor). There is another strong inversion some $250 \mathrm{~m}$ above the Zugspitze summit, and a third inversion around $z=4000 \mathrm{~m}$. The profile of specific humidity (dashed) indicates that the atmosphere below $z=1200 \mathrm{~m}$ is very moist, decreasing to somewhat smaller values up to $z=3300 \mathrm{~m}$, and then decreasing to much smaller values above. The strong inversion just above the summit level is in distinct contrast to the situation on 6 October.

\section{Conclusions}

This paper reports about comprehensive observations which were taken in order to investigate banner clouds at Mount Zugspitze. The observations are partly complementary providing both climatological information regarding the general occurrence of banner clouds as well as detailed measurements from two specific banner cloud events.

From our climatological analysis, we obtained the following results for the banner clouds at Mount Zugspitze:

- They typically last for less than an hour (40 min on average), but the distribution has a long tail with rare events extending over several hours. 

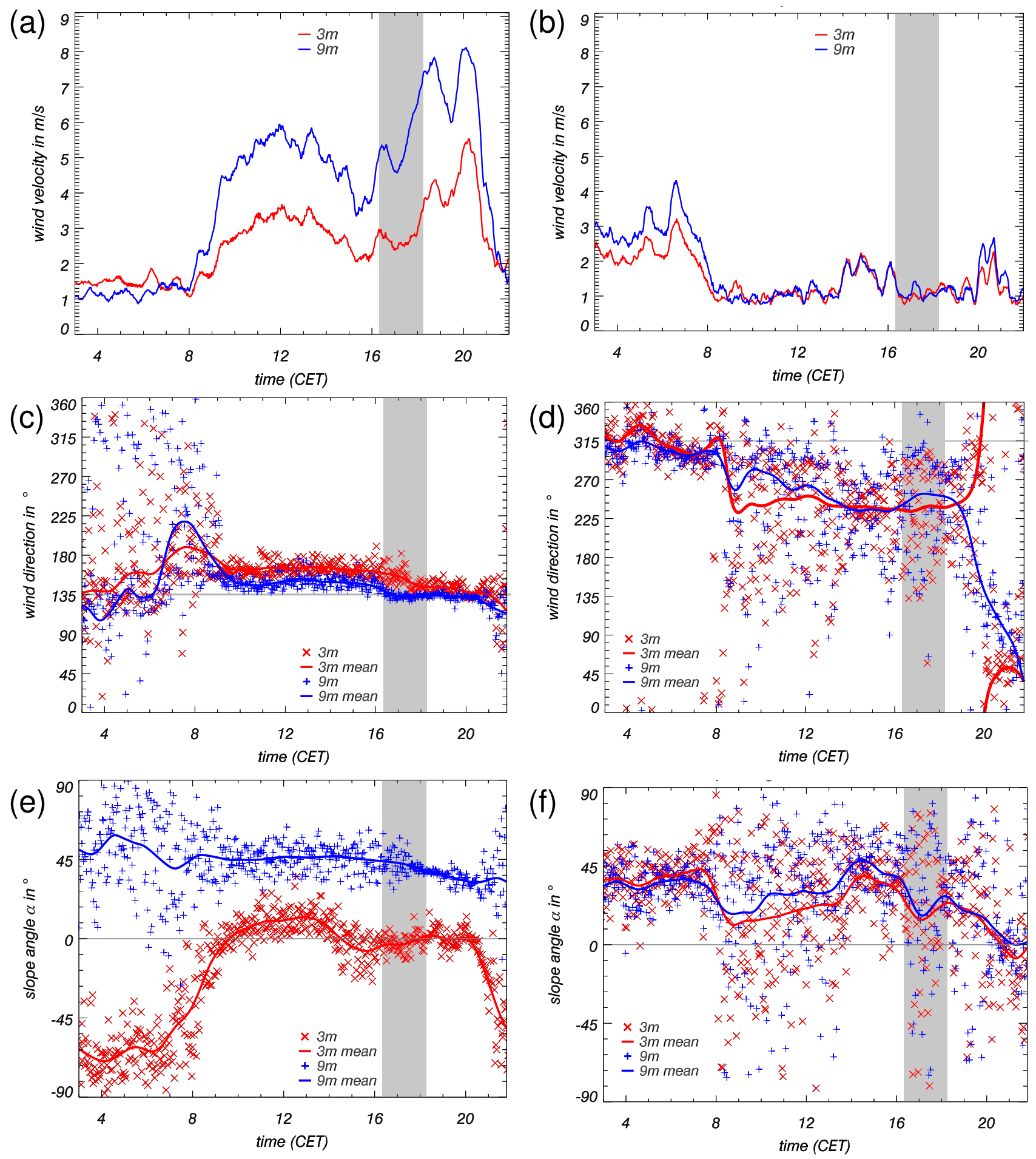

Fig. 11. Same as Fig. 9, but for 11 October 2005.

- They have a distinct diurnal cycle with a significantly higher chance of occurrence in the afternoon than in the morning. For this result it turned out essential to ac-

count for the change in daylight time as the seasonal cycle progresses.

- The frequency of occurrence has a distinct seasonal cycle (even when calibrated with respect to the varying 
(a)
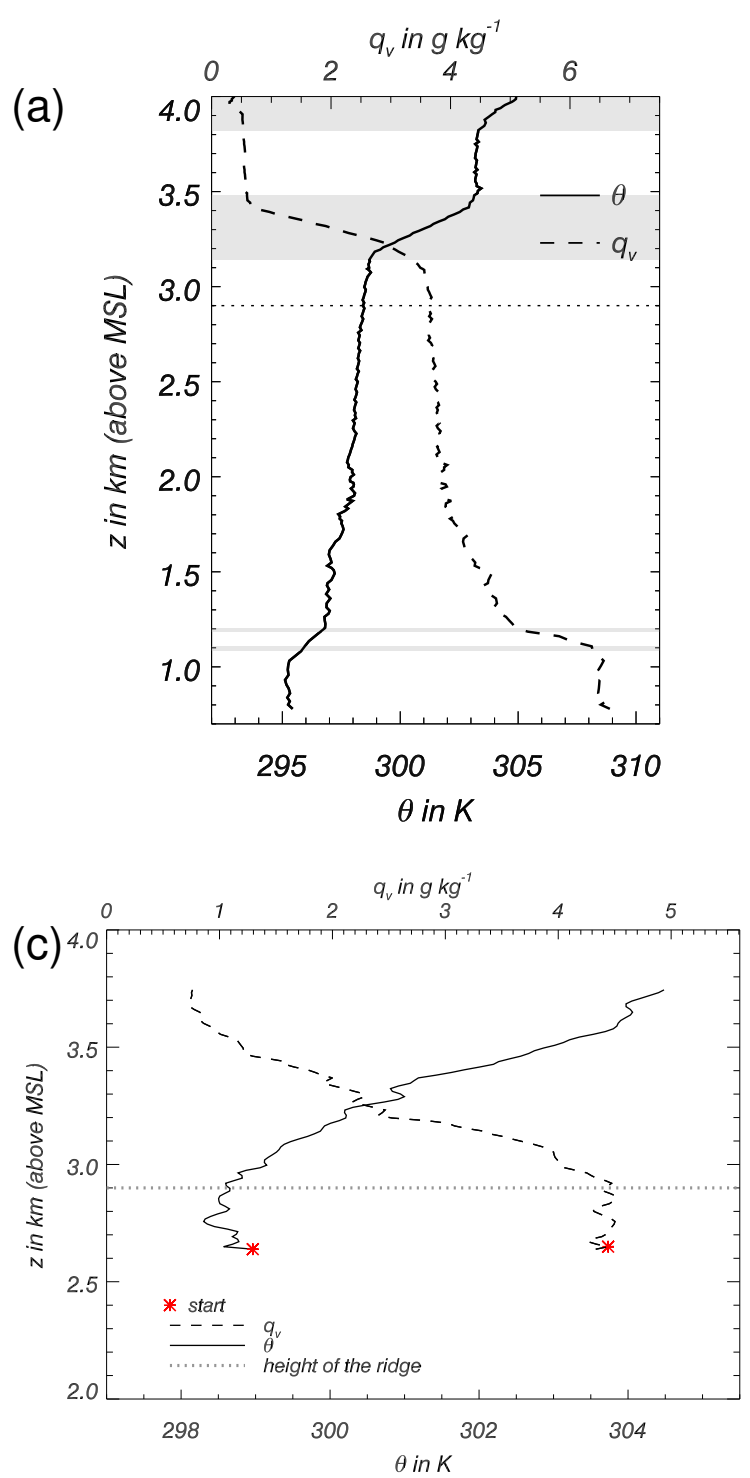

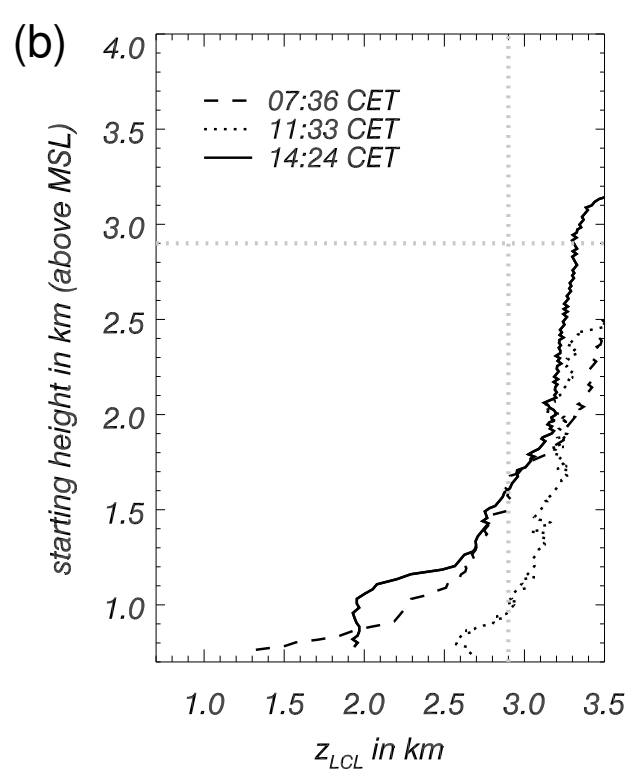

(d)

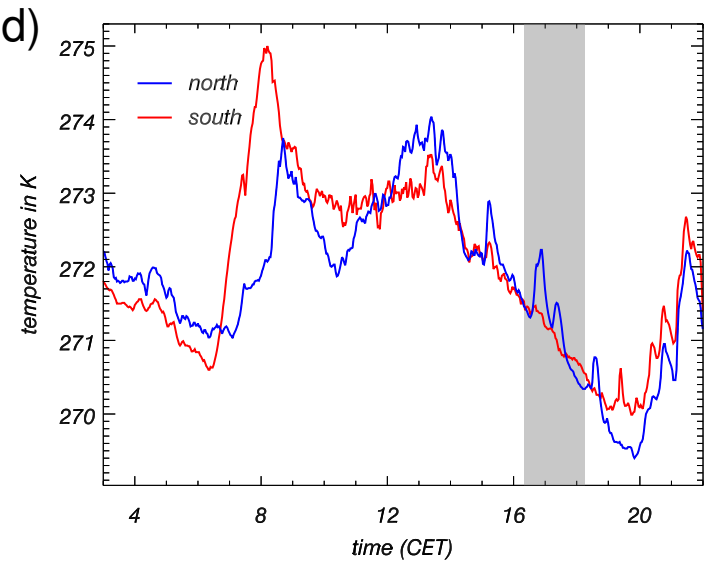

Fig. 12. Same as Fig. 10, but for 11 October 2005. The radiosonde ascent in (a) was at 14:24 CET (launch time), corresponding to the solid line in panel (b). The Kali flight in (c) was at 15:00 CET (launch time); this panel shows both potential temperature (solid) and specific humidity (dashed).

length of the day), with an increased frequency during the warm season and a decreased frequency during the cold season.

- Both the diurnal and the seasonal cycle of banner cloud occurrence have close analogs in similar behavior of climatological relative humidity. This suggests that the moisture availability is a key ingredient with higher moisture conditions favoring banner cloud occurrence on average.

- The banner clouds do not have any significant preference regarding wind speed. However, there is a slight preference regarding wind direction, favoring southeasterly flow and avoiding northerly flow.

Our time lapse movies do not allow to make any statement about the occurrence of banner clouds at night. The basic dynamical processes which are believed to be important for banner cloud occurrence are independent of the presence of daylight. This suggests that banner clouds occur also during the night, and indeed beautiful samples of this phenomenon have been observed repeatedly by one of us (M. Kristen). On the other hand, thermodynamic conditions, in particular the availability of moisture at the summit level, changes both with season and with the time of day (which is reflected in 
the pronounced diurnal and seasonal cycles of banner cloud occurrence that we obtained). The rate of occurrence at night may, therefore, differ from the rate of occurrence during the day.

The slight preference of banner clouds for southeasterly wind direction, which is consistent with the report of Hauer (1949), may be associated with the complex orography of Mount Zugspitze. In particular, a vertical section cutting at right angles through the ridge, where measurements were taken, indicates a rather precipitous drop in altitude on the northern side, while the southern side is characterized by the "Zugspitzplatt", which is sort of a high plateau that only gradually leads to lower altitudes. This provokes the hypothesis that the asymmetry in terrain is responsible for the observed sensitivity regarding wind direction. We are planning to test this hypothesis using simulations with both idealized and realistic orography.

We were surprised to find banner clouds for virtually any wind speed, with no significant preference for larger values. This is in striking contrast to numerous earlier authors who unanimously contend that banner clouds tend to occur for strong wind (Hann, 1896; Douglas, 1928; Geerts, 1992a). The fact that banner clouds do not have a preference for stronger wind speed renders the Bernoulli hypothesis (see introduction) implausible. That hypothesis posits that the pressure decrease along quasi-horizontal trajectories dictated by conservation of the Bernoulli function, and the associated adiabatic cooling, may lead to banner cloud formation. If that hypothesis were to be true, banner clouds should have a preference for stronger wind speeds, because in that case the pressure drop would be larger thus increasing the likelihood for cloud formation. Our observations do not provide any indication for such a dependence, and we conclude that the Bernoulli hypothesis does probably not capture the major mechanism for banner cloud formation. The Bernoulli hypothesis appears implausible for other reasons, too. A back-of-the-envelope calculation indicates that a vertical uplift within the lee vortex on the order of $100 \mathrm{~m}$ is associated with a much larger pressure drop than an increase in wind speed on the order of a few $\mathrm{m} \mathrm{s}^{-1}$. This is also consistent with our preliminary numerical simulations, which indicate a negative pressure anomaly (with respect to a hydrostatic reference state) in the lee; although this "helps" to produce a cloud in the lee, the amplitude of this anomaly is only a few Pascals, and this is at least two orders of magnitude less than the pressure drop expected from a vertical uplift of some $100 \mathrm{~m}$.

The detailed observations of two specific banner cloud events in October 2005 featured the following results:

- The windward and the leeward side of the ridge were characterized by different wind regimes. On the windward side the wind was strong, its direction was steady, and it had vertical shear between 3 and $9 \mathrm{~m}$; on the leeward side the wind was much weaker with large scatter in wind direction and no vertical shear on average. This is consistent with Scorer (1955), who mentions "sheltered regions with almost stagnant air" in the lee of obstacles. We also found that the wind was upward on both sides of the ridge, corresponding to flow towards the ridge following the local terrain.

- The banner cloud episodes - most of the time - did not show signs of significantly changed wind regime compared to the time just before and just after the banner cloud event. This suggests that it is mostly the thermodynamic conditions (especially moisture) that were subtly different during the banner cloud event compared with before and afterwards. However, at one of the two banner cloud occurrences the termination coincided with a slight change in wind conditions, indicating that occasionally the dynamics may play a role for the onset or the termination of a banner cloud.

- The banner cloud episodes showed a windward-leeward difference in relative humidity, with the leeward side being saturated and the windward side being mostly subsaturated. Of course this is not surprising; rather, it is a simple consequence of our definition of a banner cloud, requiring that the cloud should occur on one side of the mountain (or ridge) only. More interesting was the observation that the banner cloud episodes were characterized by higher temperatures (by some 1 to $2^{\circ}$ ) on the leeward (cloudy) side compared to the windward (cloudfree) side. As a consequence, specific humidity was significantly higher on the leeward (cloudy) side compared to the windward (cloudfree) side

- The background atmosphere in both cases indicated an inversion several hundred meters above the summit of Mount Zugspitze associated with a layer of absolute stability. This clearly prevents convection to extend much beyond the summit altitude. Without such a stable layer the cloud on the leeward side might easily develop a more convective character; the latter, however, would exclude the cloud from being categorized as a banner cloud (see the definition of Schween et al. 2007).

Our observations indicating both moister and warmer air in the lee are consistent with the idealized Large Eddy Simulations of a banner cloud made by Reinert and Wirth (2009). The authors assumed a horizontally homogeneous reference (initial) atmosphere. In their simulations the pronounced asymmetry in Lagrangian vertical displacement resulted in much larger uplift on the leeward side in comparison with the windward side. The temperature excess in the cloudy air could be traced back essentially to the release of latent heat within the cloud. This view is also supported by our observations of the thermodynamic properties of the background atmosphere: in both cases higher levels were associated with higher lifting condensation levels than lower levels. It follows that a cloudy parcel at summit level must have suffered 
a larger uplift than a cloud-free parcel. Again, this is consistent with a significant difference in Lagrangian vertical displacement on the two sides of the ridge. Note that this argument implicitly assumes that the environmental atmosphere is horizontally homogeneous; our observations seem to be consistent with this assumption.

According to Reinert and Wirth (2009), favorable conditions for banner clouds include both a (dry) dynamical aspect and a (moist) thermodynamical aspect. The present work suggests that given suitable orography and wind direction, the dynamical conditions are rather easy to satisfy. In addition, however, the moisture conditions, too, must be just right, and this seems to be the harder to satisfy. In particular, the free atmosphere at Mount Zugpitze in winter is often rather dry on otherwise cloud-free days, which prevents banner cloud formation; in summer, on the other hand, the atmospheric boundary layer is likely to be much deeper, thus bringing moist air from below close to the summit of the mountain and increasing the likelihood for banner cloud formation. Overall, this view renders it plausible why banner clouds, albeit regularly occurring, are not a very frequent phenomenon.

We caution that some of our results may be specific to the conditions at Mount Zugspitze. For instance, it is unclear to what extent the correlations between banner cloud occurrence and relative humidity regarding the diurnal and seasonal cycle apply to other mountains. Similarly, the preference of banner clouds for certain wind directions is believed to depend, at least to some extent, on the specific orography of the mountain under consideration.

In summary, this paper provided, for the first time, comprehensive observations of banner clouds at Mount Zugspitze. The observations are consistent with the notion that banner clouds essentially form in the upwelling part of a lee vortex like in the simulations of Reinert and Wirth (2009). The next steps would be to investigate to what extent the conditions at Mount Zugspitze are generic and apply to other sites of banner cloud occurrences. Progress in this direction can be made through similar observations at other sites, or through numerical simulations. The latter should benefit from the results presented in this paper.

Acknowledgements. This work involved substantial help from numerous people. The installation of the masts in the rugged terrain on the ridge would not have been possible without the support of Andreas Oppenrieder, Sonja Stängl, and Markus Garhammer. We thank the Austrian Telekom for giving us access to the power supply at their relay mast. Preliminary data analysis was done by Alexandra Mittermeyer. Essential help during the measurement campaign was provided by Markus Ablinger, Matthias Zink, Claudia Schmidt, Lars Wiegand, Hilbert Wendt, Heinz Lösslein and Robert Goler. The Kali airplane was operated by Hans Aschenbrenner and Phillip Kolb. We thank Julia Schreiber for evaluating the banner cloud movies. The German Weather Service kindly provided the data from the summit of Mount Zugspitze. This work was supported by the German Research Foundation grant Wi 1685/5-1, Wi 1685/5-4, and RE 1710/1-1.

Edited by: T. J. Dunkerton

\section{References}

Beer, T.: Atmospheric Waves. Adam Hilger Ltd., London, 315 pp., 1974.

Douglas, C.: Some alpine cloud forms, Quart. J. Roy. Met. Soc., 54, 175-178, 1928.

Egger, J., Bajrachaya, S., Egger, U., Heinrich, R., Reuder, J., Shakya, P., Wendt, H., and Wirth, V.: Diurnal winds in the Himalayan Kali Gandaki valley. Part I: Observations, Mon. Wea. Rev., 128, 1106-1122, 1999.

Egger, J., Heinrich, R., Kolb, P., Mech, M., Reuder, J., Schween, J., Wendt, H., Bajrachaya, S., Shakya, P., Lämmlein, S., and Schäper, W.: Diurnal Winds in the Himalayan Kali Gandaki Valley, Part III: Remotely Piloted Aircraft Soundings, Mon. Wea. Rev., 130, 2042-2058, 2002.

Geerts, B.: The origin of banner clouds: a case of scientific amnesia?, Bull Austr. Meteorol. Ocean. Soc., 5, 6-9, 1992a.

Geerts, B.: The origin of banner clouds: a potential vorticity perspective. Preprint volume, Sixth Conference on Mountain Meteorology, American Meteorological Society, Portland, Oregon (USA), 97-98, 29 Sept-2 Oct, 1992.

Glickman, T. S.: Glossary of Meteorology, American Meteorological Society, 855 pp., Boston, Massachusetts, USA, 2nd Edn., 2000.

Grant, H. D.: Clouds and Weather Atlas, Cowand-McCann, 294 pp., New York, USA, 1944.

Hann, J.: Allgemeine Erdkunde, Druck von Gebrüder Stiepel, Reichenberg, 1896.

Hauer, H.: Ein schauerauslösender Sogeffekt auf der Zugspitze, Met. Rundschau, 2, 326-327, 1949.

Hindman, E. E. and Wick, E. J.: Air motions in the vicinity of Mt. Everest as deduced from pilatus porter flights, Technical Soaring, 14, 52-56, 1990.

Humphreys, W. J.: Physics of the air, McGraw-Hill, 1st Edn., 702 pp., The Franklin Institute Press of J. B. Lippincott Company, Philadelphia, 1920.

Huschke, R. E. (ed.): Glossary of Meteorology. American Meteorological Society, Boston, Massachusetts (USA), viii + 638 pp., 1959.

Küttner, J.: Erinnerungen 1945-1948, in: Die Geschichte der Wetterstation Zugspitze; Geschichte der Meteorologie, edited by: Wege, K., 4, 70-75, Selbstverlag des Deutschen Wetterdienstes, Offenbach/Main, Germany, 2000.

Peppler, W.: Hinderniswolken am Säntisgipfel, Das Wetter, 44, 212-213, 1927.

Reinert, D. and Wirth, V.: A new LES model for simulating air flow and warm clouds above highly complex terrain, Part II: The moist model, Bound.-Lay. Meteorol., 133, 113-136, 2009. 
Schween, J. H., Kuettner, J., Reinert, D., Reuder, J., and Wirth, V.: Definition of "banner clouds" based on time lapse movies, Atmos. Chem. Phys., 7, 2047-2055, doi:10.5194/acp-7-2047-2007, 2007.
Scorer, R. S.: Theory of airflow over mountains: IV - separation of flow from the surface, Quart. J. Roy. Met. Soc., 81, 340-350, 1955. 